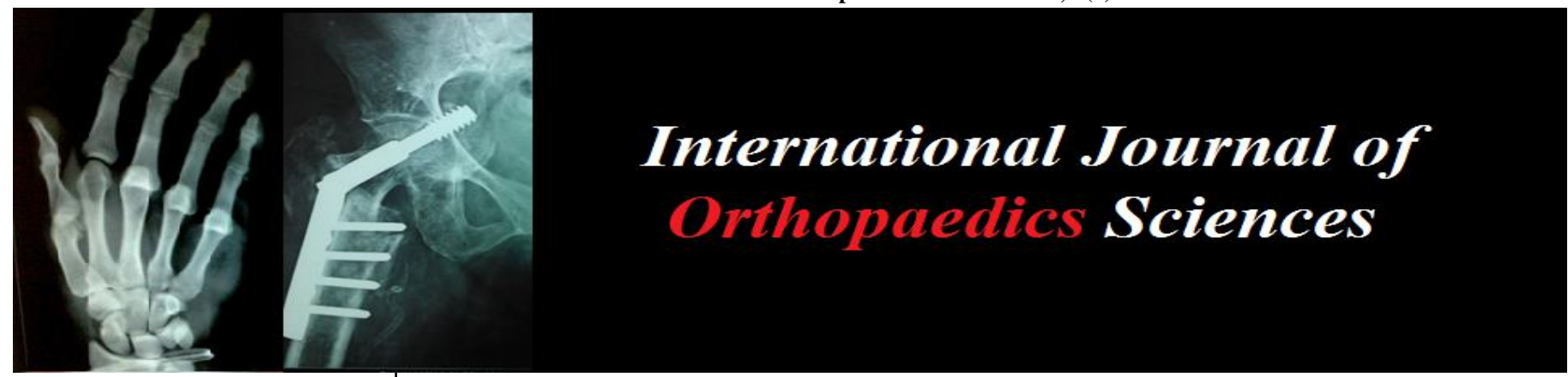

ISSN: $2395-1958$

IJOS 2018; 4(3): 477-480

(C) 2018 IJOS

www.orthopaper.com

Received: 23-05-2018

Accepted: 24-06-2018

Dr. Ravijeet Prakash

Post Diploma DNB Department of Orthopaedics, Tata Main

Hospital, Jamshedpur

Jharkhand, India

Dr. Shashi Kant Kumar Singh Senior Resident, Department of Orthopaedics, RIMS, Ranchi Jharkhand, India

Dr. Ankur Ojha

$3^{\text {rd }}$ yr. Junior Resident Academic Department of Orthopaedics, RIMS, Ranchi Jharkhand, India

Dr. LB Manjhi

Prof, Head of Department

Department of Orthopaedics,

RIMS, Ranchi Jharkhand, India

Correspondence

Dr. Ravijeet Prakash

Post Diploma DNB Department

of Orthopaedics, Tata Main

Hospital, Jamshedpur

Jharkhand, India

\section{Functional outcome of intertrochanteric fracture of femur managed surgically with proximal femoral nail (PFN)}

\author{
Dr. Ravijeet Prakash, Dr. Shashi Kant Kumar Singh, Dr. Ankur Ojha \\ and Dr. LB Manjhi
}

DOI: $\underline{\text { https://doi.org/10.22271/ortho.2018.v4.i3i.83 }}$

\section{Abstract}

Background: Intertrochanteric fracture is one of the most common fractures of the hip especially in the elderly with osteoporotic bones. The goal of treatment of these fractures is stable fixation, which allows early mobilization of the patient. Multiple modalities of treatments are available, since the fracture patterns are not uniform and the morphology has significant variations. Using PFN for fracture fixation has less blood loss, improved early mobilization, and reduced rate of infection was noted in among these patients. Aim of our study is to determine the functional outcome of intertrochanteric fractures of femur managed with proximal femoral nailing.

Material and Methods: A prospective, non-controlled, non-randomized, non-blinded observational study, on patients with intertrochanteric fractures of the femur admitted in Department of Orthopaedics, RIMS, Ranchi during two years time interval (from $1^{\text {st }}$ October 2015 to $30^{\text {th }}$ September 2017) in the age group of 40 to 88 years with a mean age of 70.68 years was conducted. 50 Patients were selected for the study from those presenting to our hospital. The outcome was assessed based on Harris Hip Score and complications in our study.

Results: Results were analysed according to Harris Hip Score. Excellent results were achieved in 14 $(28 \%)$, good results in $30(60 \%)$, fair results in $6(12 \%)$ and poor result in $0(0 \%)$ of the cases. Mean final HHS of $85.92 \pm 4.88$ was recorded among the study group. Few complications like; superficial infection, shortening of limb, reverse $\mathrm{z}$ effect and screw breakage were reported among the patients. Despite these complications the overall functional result was good; suggesting that proximal femoral nailing is an effective treatment modality in intertrochanteric fractures of femur.

Conclusion: Short Proximal Femoral Nail provides good fixation for intertrochanteric fractures if proper preoperative planning, good reduction and surgical technique are followed, leading to high rate of bone union and minimal soft tissue damage.

Keywords: Proximal femur, intertrochanteric fracture, proximal femoral nail

\section{Introduction}

Intertrochanteric fracture is one of the most common fractures of the hip especially in the elderly with osteoporotic bones. Many treatment options are described aiming for stable fixation, which allows early mobilization of the patient as they are unable to even partially restrict weight bearing. The most widely used extramedullary implant -the dynamic hip screw (DHS) - seems to have a biomechanical disadvantage when compared with intramedullary devices because the load bearing in the proximal femur is predominantly shared by the calcar. For stable fractures the

biomechanical disadvantage of the DHS does not appear to result in a significant difference in failure rate, and the DHS is therefore preferred because it is familiar and relatively cheap. However, for unstable trochanteric and subtrochanteric fractures the failure rate for a DHS is reported to be as high as $21 \%{ }^{[9]}$. Among the fractures in upper end of femur, trochanteric and sub trochanteric fractures account for more than half of the hip fractures in elderly. These fractures are seen usually in 6 th $-7^{\text {th }}$ decade, frequently resulting from simple fall. As compared to conservative treatment, operative treatment is better tolerated by elderly because of greater comfort, early mobilization of patient, lowered morbidity and mortality of patient. 
In subtrochanteric fractures operative treatment is imperative as there is limited role for conservative management. Using PFN for fracture fixation has less blood loss, improved early mobilization, reduced rate of infection and mal union was noted in among these patients. Aim of our study is to determine the functional outcome of intertrochanteric fractures of femur managed with proximal femoral nailing.

\section{Materials and Methods}

A prospective, non-controlled, non-randomized, non-blinded observational study, on patients with intertrochanteric fractures of the femur admitted in Department of Orthopaedics, RIMS, Ranchi during two years time interval (from $1^{\text {st }}$ October 2015 to $30^{\text {th }}$ September 2017) in the age group of 40 to 88 years with a mean age of 70.68 years was conducted. 50 Patients were selected for the study from those presenting to our hospital.

\section{Inclusion Criteria}

- $\quad$ Age group : Skeletally matured patients

- Gender: Male and female patients.

- Patients with acute post-traumatic fractures.

- Patients who are willing to participate in the study

- Patients who are fit for surgery

\section{Exclusion Criteria}

- Patients with Open fractures

- Patients with pathologic fractures

- Patients with other fratures in upper and lower limbs which will hamper mobilization of the patient after surgery.

- $\quad$ Patients not willing for surgery.

- Patients with neurological and psychiatric disorders that preclude reliable assessment.

The data was collected with informed consent for the study from patient and their relatives by interview and analyzing records. Radiographs of pelvis with both hips anteroposterior view and lateral view were taken and fractures were classified according to the Boyd and Graffin classification. Patients underwent closed reduction and internal fixation with proximal femoral nail for the sustained fractures under spinal anaesthesia.

\section{Surgical Technoique}

A $3 \mathrm{~cm}$ incision is made proximal to the tip of greater trochanter slightly bent dorsally. The tip of trochanter is felt with finger. After confirming the anatomical reduction, entry point is made with bone awl over the tip of greater trochanter. By confirming the position in AP and lateral view, the awl is driven just proximal to the level of lesser trochanter. A $3.2 \mathrm{~mm}$ guide wire is inserted and driven into the distal fragment. Proximal reaming done with $15 \mathrm{~mm}$ cannulated awl upto $7 \mathrm{~cm}$ distally to accommodate the proximal portion of the nail. Distal reaming done $1 \mathrm{~mm}$ more than the desired diameter of the nail. The nail closely matching to the neck shaft angle of the unaffected hip is assembled in the zig. The nail is inserted over the zig by hand by gentle twisting movements. The PFN is inserted to the appropriate depth to allow placement of two screws within the femoral neck. The guide wire is removed. Under C- arm control the guide pins for the lag screw and derotation screw are driven in through guide pin sleeves upto $5 \mathrm{~mm}$ from the articular surface of the femoral head. The lag screw and derotation screw of appropriate length is inserted after drilling with cannulated drill bit. The derotation screw should be 10 to $15 \mathrm{~mm}$ smaller than the lag screw to avoid ' $\mathrm{Z}$ ' effect. Distal targeting is done with distal targeting guide and drill sleeves using $4.0 \mathrm{~mm}$ drill bit Postoperative physiotherapy was followed according to the protocol to evaluate the functional outcome. Patients were followed up at 1st post-operative day, 6weeks, 3 months and 6 months after the surgery.

The final results were evaluated using the Harris Hip Score (HHS): This system is based on 100 units. It consists of 4 components: Pain (0-44), Function (0-47), Absence of deformity (0-4), and Range of motion (0-5).

\section{Results}

This study consisted of total 50 patients. In the present study maximum numbers of patients were found to be in sixth and seventh decades with average age 70.7 years. There were 25 male and 25 female patients. Left side 26 (26\%) intertrochanteric fractures were more than right side $24(48 \%)$ in the present study. Mode of injury was direct fall in 42 (84 $\%)$ and RTA in $8(16 \%)$. In the present study 17 cases of B\&G type 1,2.1 cases if B\&G type 2, 7 cases of B\&G type 3, 5 cases of B\&G type 4 were included. All the patients were operated on traction table and fracture was fixed with proximal femoral nailing. Fracture union was achieved in all the patients with a mean duration of 15.65 weeks. All the cases were followed up as per protocol and findings were recorded. Results were analysed according to Harris Hip Score 12. Excellent results were achieved in 14 (28\%), good results in $30(60 \%)$, fair results in $6(12 \%)$ and poor result in 0 $(0 \%)$ of the cases. A mean flexion of $110.700 \pm 7.070$ and mean extension of $10.90 \pm 2.980$ were reported at final follow up. Mean final HHS of $85.92 \pm 4.88$ was recorded among the study group. There were statistically no significant differences between the two age groups with respect to final HHS ( $p$ > 0.05). Few complications like; superficial infection, shortening of limb, reverse $\mathrm{z}$ effect and screw breakage were reported among the patients. Despite these complications the overall functional result was good; suggesting that proximal femoral nailing is an effective treatment modality in intertrochanteric fractures of femur.

\section{Final Results Shown Among the Patients}

\begin{tabular}{|c|c|c|}
\hline Results & No. of patients $(\mathbf{n = 5 0})$ & Percentage \\
\hline Excellent & 14 & $28 \%$ \\
\hline Good & 30 & $60 \%$ \\
\hline Fair & 6 & $12 \%$ \\
\hline Poor & 0 & $0 \%$ \\
\hline
\end{tabular}

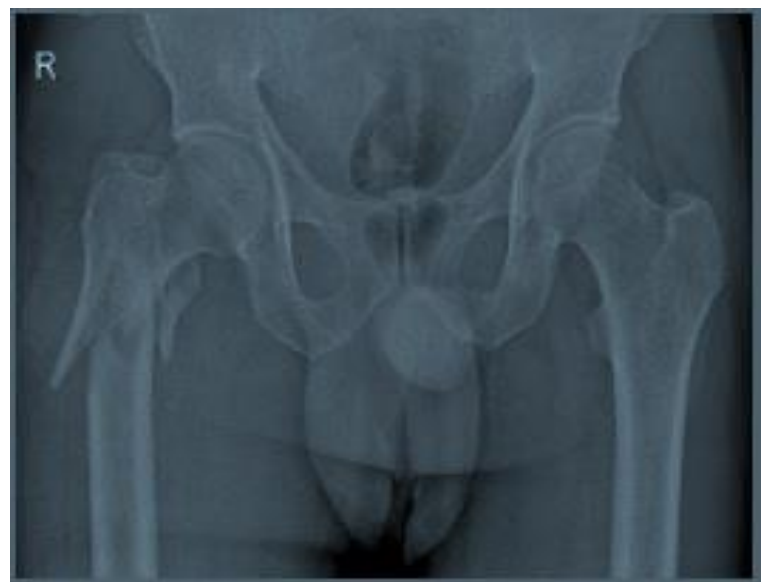

Fig 1: Pre -op X-ray 


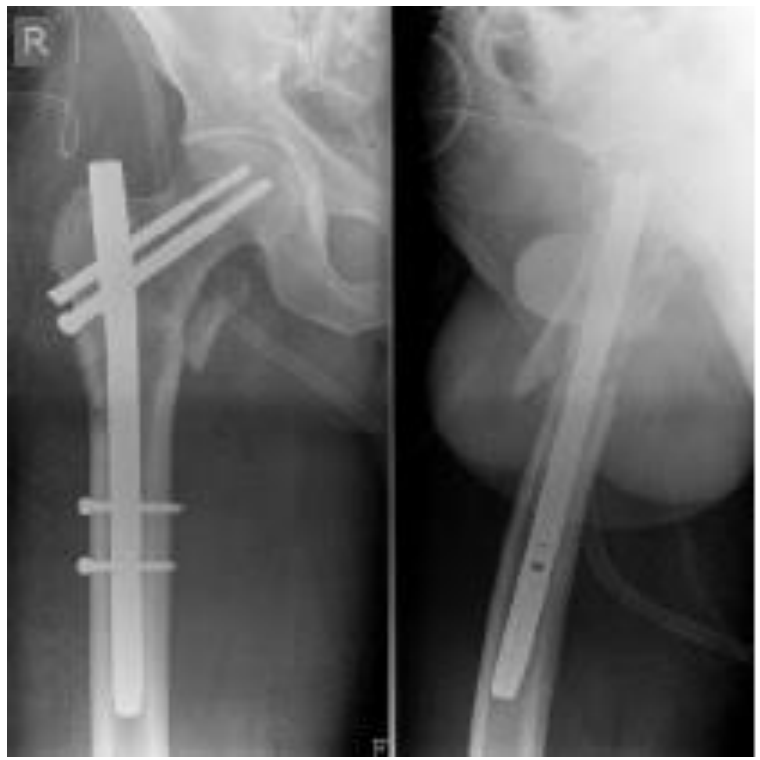

Fig 2: Post -op X-ray

\section{Complication}

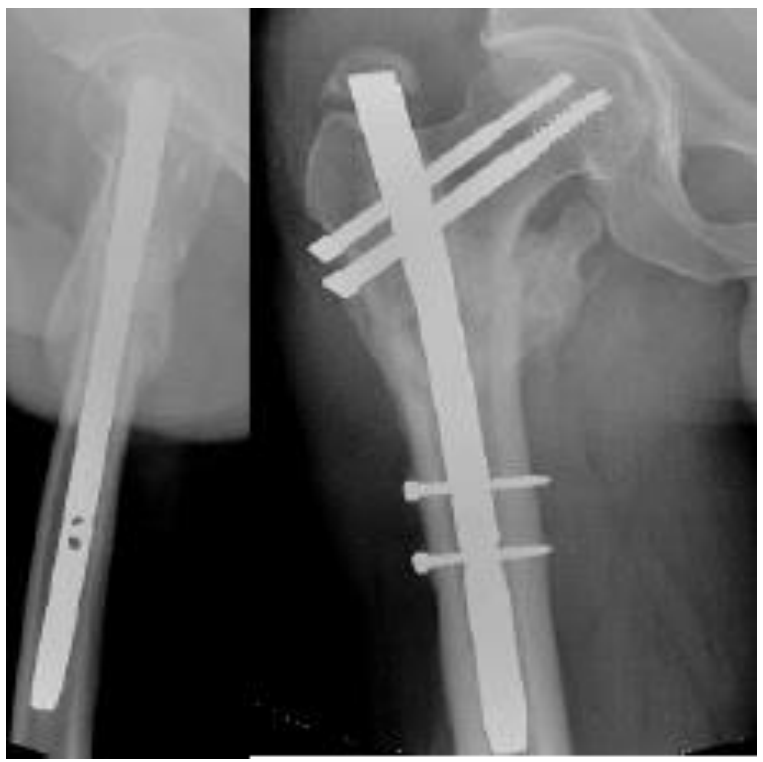

Fig 3: 6 month Follow -up
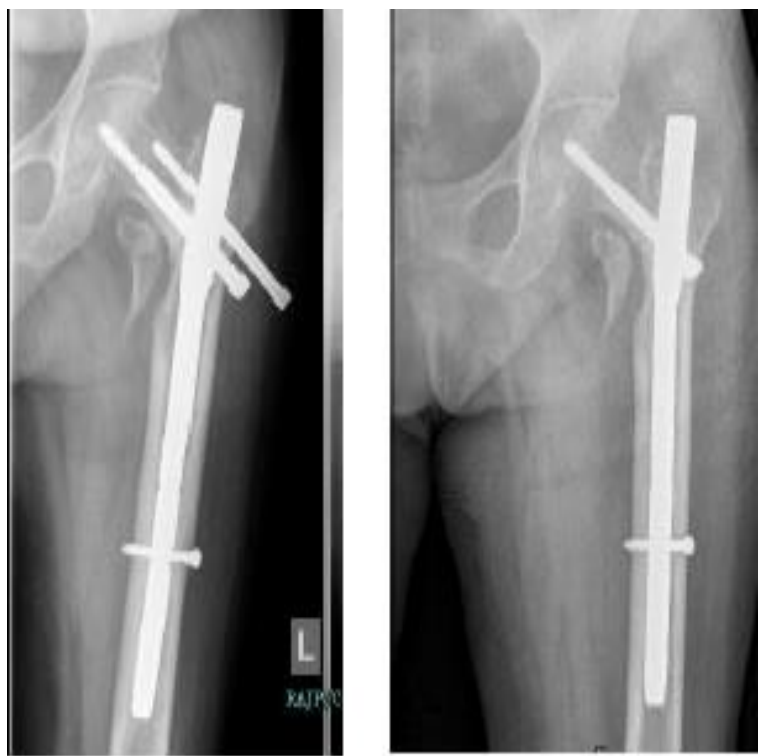

Fig 4 : Showing Reverse Z Effect And Healed Fracture After Removal Of Antirotation Screw

\section{Discussions}

Intertrochantric fractures are low energy trauma fractures seen in elderly and osteoporotic bones. Because of complex stress configuration in this region and its non homogeneous osseous structure and geometry, fractures occur along the path of least resistance through the proximal femur. Extramedullary fixation of these fractures with implants like the dynamic hip screw or the dynamic condylar screw has potential disadvantages of extensive exposure, more blood loss which then leads on to problems in fracture union and also implant failure. Intramedullary fixation is a more biological fixation and has mechanical benefits over extramedullary fixation. The implants for treatment of unstable trochanteric fractures have evolved from the biomechanical view point. The proximal femoral nail (PFN) has additional anti rotational screw and the nail tip is specially shaped to reduce the stress and to prevent low energy fracture at the tip of the implant. Compared with DHS, PFN greatly reduces the lever arm distance from the reactionary forces generated in hip joint as a result of movements at the hip joint and increases compressive forces implanted to the tension side application of DHS. The proximal femoral nail acts like an internal splint and can bear a large axial load. This allows the patient early weight bearing. As it is performed through a small surgical incision, so it is minimally invasive and reduces blood loss. Some disadvantages of the proximal femoral nail which have been reported include cutout of screws in head and neck, lateral migration of proximal screws and femoral medialization. For stable fractures, sliding hip screw there is no significant difference in failure rate when compared to PFN and so the DHS is preferred implant. For unstable fractures, the failure rate for a DHS is as high as $21 \%$. During implant removal DHS requires an extensive incision as before, periosteal stripping, post operative immobilization and chance for re fracture is high because of loss of bone stock in the proximal femur, these are not seen in PFN implant removal, which can be day care procedure also. To optimize access to the summit of the greater trochanter,the lower limb must not be placed in adduction, varizing the fracture site; rather, the trunk should be inclined laterally on the side opposite the fracture and the position maintained by a lateral thoracic support. There is a risk of over-reaming the lateral part of the proximal femur, especially when the guide is lateral to the fracture site. To avoid such excentric reaming, a slight hyper-reduction in valgus during reaming prevents the trochanter being weakened laterally and thus prevents varus displacement when introducing the nail.

\section{Conclusion}

In our study, we conclude that short Proximal Femoral Nail provides good fixation for intertrochanteric fractures if proper preoperative planning, good reduction and surgical technique are followed, leading to high rate of bone union and minimal soft tissue damage.

Intramedullary fixation has biological and biomechanical advantages over extramedullary fixation. It is a closed method thus preserves the fracture hematoma and yields early healing and early union. The procedure is less invasive, less time consuming, provides stable fixation and allows early weight bearing that in turn enhances the process of union. As our study was time bound, the patients were followed up for only 6 months. Therefore, the long-term effects of this intervention remain unknown in our cohort. A longer follow up would have made a complete assessment of this surgical intervention Our sample size reflects the routine patient inflow in our 
hospital. A study with a larger sample size, would have made a better assessment of this surgical intervention

\section{References}

1. Dimon JH, Hughston JC. Unstable intertrochanteric fractures of the hip. J Bone Joint Surg. 1967; 49A:44050. [PubMed]

2. Gulberg B, Johnell O, Kanis JA. World-wide projection for hip fractures.Osteoporos Int. 1997; 7(5):407-13.3. [PubMed]

3. Melton LJ, 3rd, Kearns AE, Atkinson EJ, Bolander ME, Achenbach SJ, Huddleston JM et al. Secular trends in hip fracture incidence and recurrence. Osteoporos Int. 2009; 20(5):687-94. [PMC free article] [PubMed].

4. Cummings SR, Nevitt MC. A Hypothesis: The Causes of Hip Fractures; J Gerontol. 1989; 44:107-111.

5. Kulkarni GS, Limaye R, Kulkarni M, Kulkarni S. Intertrochanteric fractures. Indian J Orthop. 2006; 40(1):16-23.

6. Evans EM.The treatment of trochanteric fractures of the femur. J Bone Joint Surg Br. 1949; 31B(2):190-203.

7. Menezes DF, Gamulin A, Noesberger B. Is the proximal femoral nail a suitable implant for treatment of all trochanteric fractures? ClinOrthopRelat Res. 2005; 439:221-27. [PubMed]

8. Halder SC. The gamma nail for peritrochanteric fractures. J Bone Joint Surg. 1992; 74-B:340-44

9. Werner-Tutschku W, Lajtai G, Schmiedhuber G, Lang T, Pirkl C, Orthner E. Intra-and perioperative complications in the stabilization of per-and subtrochanteric femoral fractures by means of PFN. Unfallchirurg. 2002; 105(10):881-85.

10. Bridle SH, Patel AD, Bircher M, Calvert PT. Fixation of intertrochanteric fractures of the femur. $\mathrm{J}$ Bone Joint Surg. 1991; 73-B:330-34.

11. Butt MS, Krikler SJ, Nafie S, Ali MS. Comparison of dynamic hip screw and gamma nail : A prospective randomized controlled trail. Injury. 1995; 26:615-18.

12. Harris hip score; Harris WH; JBJS. 1969; 51:1.

13. Stewart JDM, Hallett JP. Traction and Orthopaedic appliances. 2nd Edn. New Delhi: B.I. Churchill Livingstone, 1997, 3-9.

14. Siler VE, Caldwell JA. Treatment of intertrochanteric fractures of the femur by modification of Russell balanced traction. Am J Surg. 1940; 47:431-42.

15. Jewett EL. One - piece Angle Nail for Trochanteric fractures; Journal of Bone and Joint Surgery. 1941; 23:803-810.

16. Moore GH, MacEachern AG, Evans J. Treatment of intertrochanteric fractures of the femur, a comparison of the Richards screw-plate with the Jewett nailplate. J Bone Joint Surg. 1983; 65(B):262-67.

17. Boyd HB, Griffin. Classification and treatment of trochanteric fractures Arch surgery. 1949; 58:853-86.

18. Clawson DK. Intertrochanteric Fracture of the Hip", American journal of surgery. 1957; 93:580-87.

19. Clawson DK. Intertrochanteric fractures Treated by the Sliding Screw Plate Fixation Method"; Journal of Trauma. 1964; 4:733-56.

20. Dopplet SH. The Sliding Compression Screw: Today's Best Answer for Stabilization of Intertrochanteric Hip Fractures; Orthopaedic Clinics of North America. 1980; 11:507-23.

21. Sarmiento A, Williams EM. The unstable intertrochanteric fracture treatment with a valgus osteotomy and I-beam nail-plate a preliminary report of 100 cases. J Bone Joint Surg. 1970; 52(A):1309.

22. Collado F. Condylocephalic nailing for trochanteric fractures of femur. J Bone Joint Surg. 1973; 5-B:774.

23. Singh M, Nagrath AR, Maini PS. Changes in Trabecular Pattern of the Upper End of the Femur as an Index of Osteoporosis; Journal of Bone and Joint Surgery, Am. 1970; 52:457-67.

24. Medoff RJ, Maes K. A new device for the fixation of unstable pertrochanteric fractures of the hip. J Bone Joint Surg Am. 1991; 73:1192-99.

25. Aune et al. Gamma nail Vs Compression screw for trochanteric femoral fractures; Acta Orthop Scand. 1994; 65:127-30.

26. Domingo LJ, Cecilia D, Herrera A, Resines C. Trochanteric fractures treated with a proximal femoral nail. Int Orthop. 2001; 25:298-301. 